\title{
Low flows in France and their relationship to large scale climate indices
}

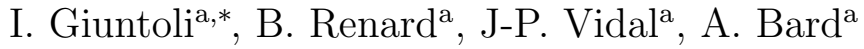 \\ ${ }^{a}$ Irstea, UR HHLY, Hydrology-Hydraulics Research Unit, \\ 3 bis quai Chauveau - CP 220, F-69336 Lyon, France
}

\begin{abstract}
This study explores the relationship between low flows and large scale climate variability in France. To this aim, a national low flow reference network of near-natural catchments, consisting of 236 gauging stations, was set up. A subset of 220 daily streamflow records for the period 1968-2008 was used to detect trends in a number of severity and timing drought indices. In addition to testing temporal trends, correlations with four climate indices were also evaluated: the North Atlantic Oscillation (NAO), the Atlantic Multidecadal Oscillation (AMO) and the frequency of two Weather Patterns corresponding to circulation types associated to wet (WP2) and dry (WP8) conditions over France. Due to their specific dynamics, NAO and WPs were also analyzed seasonally.

Results show a consistent increase of drought severity in southern France. Correlations with NAO and AMO show a similar spatial pattern. Addition-
\end{abstract}

\footnotetext{
*Corresponding author. Tel: +44 1491692550.

Present address: Centre for Ecology \& Hydrology, Wallingford, UK.

Email address: ignazio.g@gmail.com (I. Giuntoli )
} 
ally, significant relationships with WPs were found throughout France, with the exception of the Mediterranean coast. Timing indices appear to be less related to large scale climate indices, whereas some evidence of negative temporal trends was found (e.g. earlier drought start).

To assess the robustness of the above relationships, a subset of 28 stations with longer records was studied over a 60 year period (1948-2008). The results show that, when shifting the time window of the analysis, the correlations between low flow indices and climate indices remain stable, whereas those with respect to time do not.

Seasonal climate indices appear to have stronger links with low flow indices than their annual counterparts. For instance, the summer NAO shows a strong link with severity indices in the northern half of the country. This link is found again for the winter WP2.

The above results indicate that temporal trends should only be used for descriptive purposes, whereas seasonally lagged climate indices are potential candidates as predictors of summer low flows.

Keywords: low flows, trend analysis, correlation analysis, North Atlantic Oscillation, Atlantic Multidecadal Oscillation, Weather patterns

\section{Research Highlights}

1. Trend analysis for low flows in France, based on 220 stations over the period 1968-2008.

2. Correlations with large-scale climate variability (AMO, NAO, weather 
6

7

8

9

patterns).

3. Unlike correlations with climate indices, temporal trends are not stable when changing the period of analysis.

4. Lagged correlations could be used for seasonal forecasting. 


\section{Introduction}

Understanding the temporal variability of low flows is of paramount importance for water resources management, hydrological risk assessment, hydropower production, agriculture and other economic activities. This variability depends on catchment characteristics (e.g. size, geology, altitude) as well as external forcings (e.g. climate forcings and direct anthropogenic disturbances). In particular, the impact of large-scale climate variability and change has drawn significant attention over the years (e.g. Kiely, 1999;

Kingston et al., 2006; Bouwer et al., 2008; Lavers et al., 2010).

This paper aims to study the temporal variability of low flows in France, in relation to large-scale climate variability.

\subsection{Trend analyses}

At the European scale, the most complete low flow trend analysis to date was performed by Stahl et al. (2010), based on 441 catchments with more than 40 years of data. Results revealed a consistent spatial pattern of change, with generally negative trends (i.e. more severe droughts) in South and East Europe, and positive trends elsewhere. However, this general picture shows variations, depending on the hydrological regime of the studied catchments (rainfall vs. snowmelt-dominated regime). At the scale of France, the study of Renard et al. (2008), based on 90 stations over the period 1960-2000, showed no consistent trends in most parts of the country, with some regional exceptions in the Pyrenees and the Alps. 


\subsection{Relationship with large-scale climate variability}

Correlations analyses with indices quantifying large-scale climate variability have been performed by many authors. For the European region, the most relevant modes of climate variability appear to be the North Atlantic Oscillation (NAO) and the Atlantic Multidecadal Oscillation (AMO).

The NAO represents a pattern of North Atlantic climate variability. It can be quantified by an index defined as the normalized pressure difference between two stations: one over the Azores subtropical high, and one over the Iceland polar low (Hurrell, 1995). The positive phase of the NAO (NAO+) corresponds to a strong pressure gradient and is characterized by strongerthan-average westerlies associated with warm and wet winters over Northern Europe, and to a drier weather into the Mediterranean. Conversely, the negative phase (NAO-) is associated with cold and dry winters in Northern Europe, and moist air (increased precipitations) into the Mediterranean (Hurrell and VanLoon, 1997).

During positive and negative NAO phases, prevailing atmospheric conditions have an impact on river hydrology. Pociask-Karteczka (2006) proposed a review of the main links detected between the NAO and river hydrology. Several studies have been carried out at the European scale. Shorthouse and Arnell (1997) have shown that during winter positive NAO phases, winter streamflows are generally higher in Northern Europe, and, inversely, lower in Southern Europe. Similarly Bouwer et al. (2008) confirm that hydrological regimes that are most sensitive to NAO variations are located at the North- 
ern and Southern extremities of Europe, i.e. in the Scandinavian and in the Iberian peninsulas. Wrzesinski and Paluszkiewicz (2011) classified European river profiles according to the dependence between streamflow and the intensity of the NAO.

These general results have been confirmed by studies focusing on specific regions, e.g. Scandinavia (Kingston et al., 2006) or the British Islands (Wilby et al., 1997; Kiely, 1999; Stahl et al., 2001). Moreover, several lagged links, particularly interesting for their potential use in seasonal forecasting, have been highlighted. In England and Wales, a negative phase of winter NAO is generally followed by a negative anomaly of fall streamflows (Wedgbrow et al., 2002). Conversely, positive phases of winter NAO are usually associated with the following characteristics:

- In Iceland, positive anomaly of mean annual streamflow of the following year (Jónsdóttir et al., 2004).

- In the Alps, low streamflows during the spring snowmelt (Stahl et al., 2001).

- In Central Europe, low streamflows in late summer / beginning of the fall (Limanówka et al., 2002; Kaczmarek, 2003; Pociask-Karteczka et al., 2003).

- In several regions of Southern Europe, pronounced summer droughts, as for instance in the Iberian Peninsula (Stahl et al., 2001; Trigo et al., 
2004; Vicente-Serrano and Cuadrat, 2007), in Romania (Stefan et al., 2004) or in the downstream Danube (Rimbu et al., 2002, 2004).

In France, the impact of the NAO on hydrological regimes remains unclear. Cassou (2004) investigated how atmospheric and oceanic systems are linked to the NAO, but without specific focus on hydrological regimes. Massei et al. (2010) is one of the few studies on hydrological impacts of the NAO in France, in which the covariation between the NAO and the Seine catchment streamflows is analyzed.

The AMO represents a pattern of Atlantic multidecadal climate variability, and refers to detrended anomalies in the Sea Surface Temperature (SST) in the North Atlantic Ocean. These anomalies are explained by fluctuations in the thermohaline circulation in the North Atlantic and account for a leading large scale pattern of multidecadal variability in surface temperature (Knight, 2005). Differently from the NAO, the AMO is characterized by longer positive or negative phases that may persist for 20 to 40 years. There have been mainly two warm (1860-1880, 1930-1960) and two cool (1905-1925, 1965-1990) phases since 1860. The AMO amplitude has been increasing since about 1990 and from 1995 onward seems to be in its warm phase (Enfield et al., 2001).

Many prominent examples of regional multidecadal climate variability have been related to the AMO (Knight et al., 2006), for instance the frequency of Atlantic hurricanes (Goldenberg et al., 2001; Trenberth and Shea, 2006; Enfield and Cid-Serrano, 2009) or the occurrence of Sahel droughts (Rowell 
et al., 1995; Rowell, 1996). The AMO has also been shown to affect North American and European summer climate (Sutton and Hodson, 2005): a positive AMO anomaly is related to decreased mean sea level pressure over the whole North-Atlantic basin, along with lower rainfall over the US and increased rainfall in North West Europe.

In North America, the influence of this climate index on the temporal variability of streamflow and precipitation has been studied extensively. Enfield et al. (2001) studied the impact of the AMO on rainfall and river flows in the continental US, finding that the warm phases are associated with negative anomalies on the majority of the country. McCabe et al. (2008) looked specifically at US droughts, showing that warm AMO phases are associated with more frequent or longer droughts in the Midwest, and with less intense droughts in Florida and in the North West. Assani et al. (2011) found a link between the warm phase of the AMO and rainfall and streamflow deficit in Quebec.

In Europe in general, the influence of AMO on temporal variability of streamflow has received less attention. Regarding the evolution of glaciers in the Swiss Alps, Huss et al. (2010) showed that the AMO is inversely correlated to the glaciers' mass balance: a positive AMO is associated with Alpine glacier mass loss, whereas during negative AMO periods glaciers experience reduced mass loss or even mass gain. In France, in particular, the impact of the AMO remains largely unknown. Noteworthy is the study by Tourre et al. (2011), who found the AMO index to have an effect on temperatures variability in 
the Paris region and on grape harvest dates in the Burgundy region.

The NAO and the AMO describe climate variability on a relatively broad scale. Considering that this study focuses on France and on rather small catchments, we also decided to use local climate variability indices. Moreover, the literature indicates that the influence of NAO and AMO is stronger at the ends of the European continent (South and North). France is located right in the middle of the two areas of influence which are affected by opposite effects.

Weather patterns (WPs, or "circulation patterns" when defined by air pressure only) are often used to describe the atmospheric situation over a region as a categorical variable, which has potential to reveal important information about the climatic mechanisms driving drought development (Fleig et al., 2011). As region-specific indices, they are potentially more explanatory than the NAO and the AMO when it comes to link climate variability to hydrology. Weather patterns are widely used in atmospheric sciences for grouping similar synoptic weather situations which lead, for a given geographical area, to similar meteorological conditions. Numerous methods of weather pattern classification are available (see e.g. Huth et al., 2008; Fleig et al., 2010; Philipp et al., 2010, and the COST733 European action for reviews and comparisons).

A number of studies revealed the interest in classifying weather patterns in hydrology. Several authors have shown the link between the rainfall distribution and weather patterns (Littmann, 2000; Boé and Terray, 2008; Lorenzo 
et al., 2008; Martínez et al., 2008; Garavaglia et al., 2010, 2011). Similar relations exist with hydrological variables (Samaniego and Bárdossy, 2007; Petrow et al., 2009), and, more specifically, with low flows [e.g. Stahl and Demuth (1999) in Germany; Pongrácz et al. (2003) in Central Europe; Fleig et al. (2011) in Denmark and the UK].

For this study, we used the weather patterns defined by Garavaglia et al. (2010), which result from a classification of atmospheric circulation patterns relevant to French climatology. The classification uses a limited number (8) of typical but contrasted synoptic situations described by geopotential fields. The data is assigned to the $8 \mathrm{WP}$ classes according to geopotential heights between 700 and $1000 \mathrm{hPa}$. Note that, although the assignment rule is solely based on geopotential information, precipitation data is also used to determine the number of classes and to initialize the clustering algorithm (see Garavaglia et al. (2010), for more details).

\subsection{Objectives and outline of the paper}

This paper aims to study the temporal variability of low flows in France, in relation to large-scale climate variability. The specific objectives are the following:

- Describe a reference dataset of 220 gauging stations suited to the monitoring of climatic effects on low flows in France.

- Update the trend analysis previously performed by Renard et al. (2008) 
by considering more gauging stations, thus providing an extended period of analysis and a markedly improved spatial coverage.

- Move beyond the sole trend analysis by attempting to link low flow variability with large-scale climate variability.

This analysis contributes to the extended literature discussed in previous sections, thus improving the understanding of the role of climate variability on low flow regimes. In particular, specific points of interest are:

- The analysis is based on an extended dataset of thoroughly inspected daily series, providing a remarkable temporal and spatial extent.

- The analysis uses hydrological indices describing drought events based on daily data rather than monthly or seasonally averaged discharges. This is of interest for a more event-based description of low flows, in particular in terms of timing and severity.

- The analysis uses several climate indices describing distinct modes of variability, at inter-annual and seasonal time scales.

- The analysis has a nation-wide spatial extent, thus contributing to a better understanding of the role of climate in low flow variability in France.

The remainder of this paper is organized at follows. Section 2 describes the data and methods used in this analysis, including the reference gauging 
stations network (section 2.2), the definition of hydrological (section 2.3) and climate (section 2.4) indices, and the statistical trend and correlation testing procedures (section 2.5). Section 3 describes the main results of this analysis, both in terms of temporal trends and correlations with climate indices. The consequences and perspectives of these results are discussed in section 4 , before summarizing the main findings in section 5 .

\section{Data and methods}

\subsection{Data requirements}

The analysis of low-flows variability is based on hydrological time series, recording river discharges at gauging stations. The importance of goodquality datasets can not be overemphasized, as recently recalled by Hannah et al. (2011). Given the various forcings controlling low flows, disentangling the effects of measurement errors, anthropogenic disturbances and climate variability/change, is a tremendous challenge. When understanding the role of climate in low flow variability is the main interest, the most tractable solution is to select gauging stations where non-climatic factors of change can be minimized (if not discarded). In particular, this requires selecting gauging stations suited to low flow measurements (e.g. with a gauging section enabling a stable rating curve), controlling near-natural catchments where anthropogenic disturbances are negligible. Moreover, long series spanning several decades are necessary if trends and relationships with large-scale climate variability are to be identified. 
Many studies in the literature have analyzed low flow variability based on such datasets. In general, these studies can be classified into two categories: (i) trend analyses, reporting the magnitude and significance of temporal trends in hydrological variables (e.g. Stahl et al., 2001; Burn and Elnur, 2002; Birsan et al., 2005; Hannaford and Marsh, 2006; Renard et al., 2008, amongst many others); (ii) correlation analyses, linking temporal variability of hydrological variables to various indices quantifying large-scale climate variability (e.g. Kingston et al., 2006; Vicente-Serrano and Cuadrat, 2007; McCabe et al., 2008; Assani et al., 2011, amongst many others).

\subsection{French Reference Low Flow Network}

Several countries have set up reference gauging networks in order to monitor the evolution of hydrological regimes and to assess the impact of climate variability and change (Whitfield et al., 2012). The UK, for instance, has set up a reference network of 120 relatively undisturbed catchments (Bradford and Marsh, 2003) which was used to assess trends in low flows (Hannaford and Marsh, 2006) and floods (Hannaford and Marsh, 2008). Similarly the French National Agency for Water and Aquatic Environments (ONEMA) set up a project for creating a nationwide reference network of trustworthy gauging stations from relatively undisturbed catchments aiming at monitoring the evolution of low flow regimes. Daily streamflow time series from the French Banque HYDRO Archive (Ministry of Environment) were selected in order to meet the following criteria: (a) at least 40 years of daily records; (b) 
the gauging station controls a catchment with no appreciable direct human influence on river flow; (c) data quality is suitable for low flow analysis.

The first selection of gauges, based on the Banque HYDRO metadata, were thoroughly inspected so that stations of low quality or not meeting the criteria were discarded. In particular, all time series were visually screened one by one in search of visual inhomogeneities. Moreover, they underwent a statistical trend and step-change analysis on a number of streamflow indices, based on the Mann-Kendall trend test (Mann, 1945; Kendall, 1975) and the Pettitt step-change test (Pettitt, 1979). Suspicious changes and trends were noted and checked through an exchange with the data providers aiming at linking anomalies to particular events (e.g. rating curve change, constructions affecting the river, occurrence of specific extreme events, change of the station location). If the change was linked to a specific cause, the station was excluded from the data set.

Finally, the Benchmark Low Flow Network ${ }^{1}$ comprises 236 gauging stations whose time availability is shown in figure 1a. Figure 1b shows the number of stations available per year. The period $1968-2008$ provides the best trade-off for data availability in time and space. Consequently, a subset of 220 stations available over the period 1968-2008 was used in this study.

Figure 2 shows the location of the selected stations. The majority of gaug-

\footnotetext{
${ }^{1}$ A subset of 209 stations is also suitable for flood analyses (Giuntoli et al., 2012). Part of this dataset is currently being transferred to the Global Runoff Data Center (GRDC, http://grdc.bafg.de/).
} 
ing stations control catchments with a rainfall-dominated hydrological regime (184), while 36 catchments have a snowmelt or mixed (snowmelt-rainfall) hydrological regime, mostly in the Pyrenees and in the Alps. Figure 1c shows the distribution of catchments areas. The selected catchments are in general relatively small, $85 \%$ of catchments being smaller than $1000 \mathrm{~km}^{2}$.

\subsection{Low flow indices}

Low flow indices were extracted from the daily streamflow series in order to quantitatively summarize the main properties of hydrological droughts: summer low flows due to low precipitation and high evapotranspiration for rainfall regimes; winter low flows due to snow and ice storage for snowmelt and mixed regimes. Different hydrological years were defined for the two types of regime in order to locate low flow periods roughly in the middle of the year. For rainfall-dominated gauges the year starts in February and ends in January of the following calendar year. For snowmelt-dominated and mixed gauges the hydrological year was set to start in May ending in April of the following calendar year. Low flows events were pooled using a low flow threshold, which was set for each station to the quantile Q15 of the interannual flow duration curve (corresponding to the flow that is exceeded for $85 \%$ of the period of record, as in e.g. Tallaksen and Van Lanen (2004)). This quantile results from the trade-off between having a sufficiently low threshold to characterize low flows, while avoiding having years with no threshold crossing. All indices were extracted yearly. For snowmelt and 
mixed regimes, analyses (not shown) were made considering two distinct low flow periods (May+6months, November +6 months): because the number of these stations is small we decided to avoid this distinction and adopt yearly indices as we did for rainfall dominated gauges.

Preliminary analyses (not shown) suggested that the following six indices provide complementary drought information (Figure 3):

1. the annual mean discharge (A Mean)

2. the annual minimum discharge (A Min)

3. the annual volume deficit below a low flow threshold (Vol. Def.)

4. the drought start (Start)

5. the drought center (Center)

6. the drought end (End)

Indices 1-3 describe the drought severity, while indices 4-6 describe the drought timing. The volume deficit index (3) is equal to the sum of the volume deficits over the whole year. Timing indices 4-6 were adapted from the concept of "center of mass" proposed by Stewart et al. (2005): indices Start, Center and End correspond to the day when the volume deficit reaches $10 \%, 50 \%, 90 \%$ of its annual value, respectively. Timing indices are expressed in number of days after the year start.

\subsection{Climate indices}

In order to study the relationship between hydrological and climatic variability, climate indices can be used to quantify the main modes of climate 
variability relevant to the French region. The indices selected for this study are two well-known large scale climate indices, the NAO and the AMO, and two weather patterns corresponding to frequent synoptic situations over France.

\subsection{1. $A M O$}

The time series for the unsmoothed AMO monthly index was downloaded from the US National Oceanic and Atmospheric Administration web site ${ }^{2}$. This monthly time series was averaged over hydrological years, yielding the annual series shown in Figure 4a. Two AMO series were used, corresponding to averaging over the two distinct hydrological years considered for the hydrological indices (see section 2.3 - only the February-January averaged series is shown in Figure 4a).

\subsection{2. $N A O$}

The time series for the NAO monthly index as defined by Jones et al. (1997) (normalized pressure difference between Gibraltar and Reykjavik stations) was downloaded from the Climate Research Unit web site ${ }^{3}$. Similarly to the AMO, averaging over the hydrological year yields the annual NAO series, as shown in Figure 4b for February-January. However, unlike the AMO index, the within-year variability of the NAO is not negligible compared with interannual to interdecadal variations. Consequently, seasonal NAO indices

\footnotetext{
${ }^{2}$ http://www.esrl.noaa.gov/psd/data/correlation/amon.us.long.data

${ }^{3}$ http://www.cru.uea.ac.uk/cru/data/nao/; accessed September 2011
} 
were also used, by averaging monthly values over the four boreal seasons: winter (DJF), spring (MAM), summer (JJA) and fall (SON).

\subsubsection{Weather Patterns}

A daily times series of WP occurrence was provided by Electricité de France (EDF, French Power Company) for the period 1953-2008 (as in Garavaglia et al., 2010). In this series, each day is assigned a WP value between 1 and 8 according to the weather pattern. WP indices can then be derived by counting the frequency of each WP within a given time-frame (a hydrological year or one of the four seasons). Two weather patterns were used in this study: WP2, associated with Atlantic westerly circulations yielding wetter-than average conditions over most of France, except in the South the Mediterranean and the Massif Central regions; and WP8, associated with anticyclonic situations yielding drier-than-average conditions over the whole country. These specific patterns were chosen because they are the two most frequent (23 and $28 \%$ of days for WP2 and WP8, respectively) and are hence likely to play an important role in the development of drought events. Figure 4c-d show the WP2 and WP8 indices, corresponding to the standardized annual frequency of WP2- and WP8-days (standardization was obtained by subtracting the mean and dividing by the standard deviation computed over the whole period of record 1953-2008). Similarly to the NAO, seasonal indices were also derived by restricting the computation of WP frequencies to the four boreal seasons. 


\subsection{Trend and correlation tests}

As in other studies (Stahl et al., 2010; Wilson et al., 2010), this paper aims to present the overall regional patterns of streamflow evolution and variability. To this aim, the existence of trends in the hydrological indices defined in section 2.3 was evaluated. Moreover, correlations between hydrological indices and climate indices (section 2.4) were explored.

Since the distribution of hydrological indices may be difficult to elucidate (it may vary from one index to the next, and from station to station), non-parametric testing procedures were used. The Mann-Kendall trend test (Mann, 1945; Kendall, 1975) was used for evaluating the presence of trends in the low flow indices series. The modification suggested by Hamed and Rao (1998) to account for potential autocorrelation was implemented. Correlations between hydrological and climate indices were tested using the Kendall's tau test (Kendall, 1938). This test evaluates whether the Kendall's tau between two variables (here, climate index $X$ vs. hydrological index $Y$ ) significantly differs from zero. The Kendall's tau is a rank-based alternative to the Pearson linear correlation coefficient, which may be more relevant for non-linear associations and/or markedly non-Gaussian data.

Both tests are based on ranks and therefore do not make any assumption on the distribution of data. Note that the Mann-Kendall test is a particular case of the Kendall's tau test, obtained by replacing the climate index $X$ by a time index (e.g. $1, \ldots, n)$. From this point of view, the trend analysis can be considered as a particular correlation analysis with the time used as 
covariate in lieu of the climate index.

The analysis was carried out in three steps:

1. Correlations between annual climate indices and hydrological indices were sought for 220 stations over the period 1968-2008.

2. Same as 1. for a subset of 28 long series covering the period 19482008. Three periods of analysis were considered: 1948-1988 (40 years), 1968-2008 (40 years) and 1948-2008 (60 years). The objective was to assess the stability of detected trends and correlations when changing the period of analysis. Note that data were not available before 1953 for correlations with WPs.

3. Correlations between seasonal climate indices (NAO, WP2 and WP8) and hydrological indices were sought for 220 stations over the period 1968-2008. This analysis was performed in order to evaluate the existence of lagged correlations (e.g. between a characteristic of the summer drought and a climate index computed over the preceding winter) which are of interest for seasonal forecasting purposes. For the majority of the stations (rainfall regime), the hydrological year starts in February and low flows occur mainly in the summer (June-August), so the seasons with a lag are primarily the winter, and to a lesser extent, spring and fall. For the remainder of the stations (mixed and snowmelt) the hydrological year starts on May. For mixed regime stations, low flow periods are in summer and winter, so the lagged seasons are the preceding winter and spring, and the fall of the same year. For purely 
snowmelt stations, the main low flow period is fall through winter, so the lagged seasons are the preceding winter and spring, and the summer or the same year.

For each station, the values of hydrological indices are considered as missing for years with more than $10 \%$ of missing daily data.

\section{Results}

The results are presented through maps of the spatial variability of the trends/correlations, as in Figure 5. Significant correlations are shown with color dots, blue (negative correlation) and red (positive correlation) for rainfall regime, green (negative correlation) and brown (positive correlation) for snowmelt regime. The distinction is made because the two regime types are calculated over different hydrological years. The legend shown in Figure 5 applies to all figures of this section.

\subsection{Year-to-year links: annual climate indices}

The results for year-to-year links between climate and low flow indices are presented at the hydrological year scale (period 1968-2008). Figure 5 shows the results of the Kendall tests for, on the one hand, the three severity indices (annual mean flow, annual minimum flow, volume deficit) and, on the other hand, the four annual climate indices and time. On the first column of this figure the temporal evolution is shown. The next neighboring columns 
describe the association with the climate indices. Moreover, Table 1 gives the percentages of significant correlations (at 10\% error level). In terms of temporal evolution, the first column of Figure 5 highlights a distinct North-South pattern: significant trends toward more severe low flows were detected for many stations in the Southern half of France, while most stations of the Northern half show no significant trends. The new study confirms the trend towards more severe droughts that was found in SouthWestern France by Renard et al. (2008), but this trend in now more clearly apparent over all Southern France.

The most striking results are the consistent correlations detected between the hydrological indices and the weather patterns WP2 and WP8. These correlations are found over the whole territory with the exception of the Mediterranean coastal region. They are highly significant for the annual mean flow, a little less for the annual minimum flow and the volume deficit, but preserving a remarkable spatial homogeneity. The sign of the correlations is sound with the interpretation of the indices WP2 and WP8: a high value of WP2 corresponds to a high frequency of wet weather "western circulation", leading to high values of annual mean and minimum flow, and low values for volume deficit. A similar reasoning applies to the WP8, corresponding to a dry weather.

Correlations were also detected for the AMO. The spatial pattern is similar to the one observed for temporal trends (first column), especially in the mountainous areas of the Pyrenees (South-West) and the Cevennes (Center- 
South). This is particularly interesting, and suggests that, for these regions, detected temporal trends could partly result from the correlation with the AMO. Indeed, the AMO has seen an overall pronounced increase in the study period (1968-2008, see 4a). A hydrological index correlated with the AMO would be expected to have a similar temporal trend. Nonetheless, if this trend does stem from the AMO, it may disappear over a longer period, with the AMO's variability. This possibility will be examined further with the stability of correlations assessed over different periods (following section). The correlations with the NAO are mainly found for the center of France. In particular, a cluster of significant correlations was detected with the annual mean flows for the Cevennes (Center-South) region.

Results for the three timing indices are shown in Figure 6. On the whole, correlations with climate indices are less prominent compared to the previous severity indices. In particular, the influence of NAO and AMO is weak and does not have a specific spatial pattern. Correlations with WP2 and WP8 are more numerous, especially for the drought start and end, and are spatially coherent: years with high frequencies of dry weather WP8 correspond to an earlier drought start (in the Center and in Brittany), and a later drought end (in the North and the Pyrenees), and inversely for WP2. Figure 6 also shows that a number of temporal trends exist for drought timing (first column), the drought start in particular, but the spatial pattern does not match any of the climate indices patterns. This suggests that temporal trends in drought timing are not affected by climate variability. 


\subsection{Year-to-year links: stability of hydro-climatic links}

A subset of 28 long series, covering the period 1948-2008, was used to assess the stability of detected correlations for different time periods. Figure 7 shows temporal trends detected over the periods: (i) 1948-1988 (40 years); (ii) 1968-2008 (40 years, same as the analysis in the previous section); (iii) the entire period 1948-2008 (60 years).

For simplicity the results shown are limited to three hydrological indices: annual mean flow, drought start, and volume deficit. Temporal trends are visibly not stable from one period to the next: for the annual mean flow, for instance, the 1948-1988 analysis suggests a positive trend, but this trend is reversed over the subsequent period 1968-2008, and fades away over the entire period 1948-2008. When comparing the periods lasting to 2008, what is detected in the short period 1968-2008, is barely found in the long period 1948-2008, or, in the case of Volume Deficit, detections are not found in the same areas. The same lack of stability is observed in the other hydrological indices.

The analysis was also carried out using the climate indices. For the AMO (results not shown) the regions where this index has an influence (Pyrenees, Cevennes) are underrepresented among the available data set of 28 stations. No clear correlation pattern was therefore detected consistently over the different periods.

The results for the NAO are more conspicuous (Figure 8): the correlations detected over the three periods remain consistent. The influence of the NAO 
on annual mean flows in the center of France remains visible over the three periods. For the drought indices the influence is much smaller, but still consistent over the three periods.

Lastly the results for the WP8 show a good stability of the correlations (Figure 9): the correlations WP8-annual mean flow and WP8-volume deficit remain consistent no matter the period of analysis. Similar results were found for the WP2 index (not shown).

The lack of stability of temporal trends stands in contrast with the fairly good stability of correlations with climate indices (when they exist) and accounts for an important result which leads to several remarks. Firstly, this result confirms that the detected temporal trends should not be extrapolated into the future, or at least not on the basis of the results presented in this study. Conversely, although more stations and longer periods are required to corroborate this hypothesis, the fact that the links climate-hydrology remain stable, is per se an indication of the suitability of climate indices to explain the temporal variability of hydrological regimes.

As discussed in section 3.1, the temporal trends detected on hydrological regimes could originate (at least partly) from a dependence to large scale climate variability, on the basis of the following rationale: (i) hydrological indices depend on climate indices; (ii) some climate indices have a strong temporal inertia, which can create apparent trends on short periods of a few decades (especially for the AMO); (iii) some temporal trends detected on hydrological indices could indeed result, at least in part, from the inertia of 
the climate indices.

\subsection{Lagged links: seasonal climate indices}

Correlations between low flow indices and seasonal climate indices are now presented with specific focus on lagged correlations (e.g. a winter or spring climate index with a high correlation with summer droughts). This type of correlation can pave the way for seasonal forecasting applications.

Figure 10 shows the Kendall test results between the six hydrological indices (rows) and the four seasonal NAO series (columns). As highlighted in section 1.2, the winter NAO (first column), during its positive phase, is associated with higher flows in Northern Europe (Shorthouse and Arnell, 1997), and conversely, with more pronounced droughts in the Iberian Peninsula (VicenteSerrano and Cuadrat, 2007). None of these links are visible in France: all severity indices (annual mean and minimum flows and volume deficit) are scarcely correlated to winter NAO. Some correlations are detected for timing indices but in a dispersed fashion. Contrary to what is observed in Northern and Southern Europe, it appears that French hydrological regimes are barely influenced by winter NAO.

The next noticeable result is the strong link between summer NAO and severity indices (annual minimum flow and volume deficit) detected for the Northern half of the country. This prominent link opens new interesting perspectives for seasonal forecasting. This point will be further discussed in the discussions section. 
Overall, the seasonal scale allows highlighting correlations more prominently than at the annual scale. When looking at severity indices, the annual scale (Figure 5) does not show the compelling correlations found at the seasonal scale (Figure 10) for the summer NAO. It is thus convenient to consider this mode of variability at the finer scale of seasons.

The results obtained for the seasonal WP2 are shown in Figure 11. The large number of lagged correlations detected for the Northern half of the country between winter/spring WP2 and the hydrological indices of drought severity (and the timing indices to a lesser extent) is not surprising: it occurs during a period of high flows when groundwater storages have been replenished by winter precipitation. As discussed previously, this result brings about interesting perspectives for seasonal forecasting. This is especially true for the WP2, as lagged correlations provide information on upcoming low flows without the need to predict the climate index.

As for the WP2, numerous correlations are detected between seasonal WP8 and the hydrological indices (Figure 12). However, unlike WP2 and summer NAO, the correlations are not limited to the Northern half of France but stretch out to the South as well. The most pronounced correlations are:

- The annual mean flow and the fall WP8, mainly in the center of France and in Brittany (North West).

- The drought severity indices and winter/spring/summer WP8, over the majority of the country, except the Pyrenees, the Alps and the 


\section{Mediterranean coast.}

- The drought timing indices and WP8. The drought start is strongly correlated with the spring/summer WP8, whereas for the drought center and end the strongest correlation is with the fall WP8.

\section{Discussion}

The results of the analysis demonstrate that the response of low flows to climate large-scale variability varies spatially and temporally. This section discusses the consequences of these findings, both in terms of limitations and opportunities.

\subsection{Trends vs. climate-induced oscillations}

When considering temporal trends, drought severity increases in Southern France, and this result is in agreement with those of Stahl et al. (2010). However, correlations with the AMO and NAO indices follow a similar spatial pattern (although with less detections), suggesting that, to a certain extent, trends in drought severity could result from the low-frequency variability of AMO and NAO. Conversely, drought timing indices show numerous downward trends, whereas correlations with AMO, NAO and WPs are less pronounced and do not show a similar spatial pattern.

In the stability of hydro-climatic links analysis (section 3.2) we assume that, if oscillating/quasiperiodic trends exist, they are found in the hydrological indices, and they are the result of oscillating/quasiperiodic trends in climate 
indices. Interestingly, the reversed temporal trends detected over different time windows from long series, are similar to those seen in a comparable analysis conducted by Hannaford and Buys (2012) in the UK. The authors assessed trends via a moving window trend analysis and found trends shifting from largely positive to negative around 1965, suggesting that large-scale atmospheric circulation changes may be responsible.

These observations highlight the difficulties in distinguishing between longterm trends and low-frequency variability based on relatively short series. This is problematic because operational consequences (e.g. updating frequency analysis procedures to account for non-stationarity) very much depend on the actual type of evolution affecting the data. This ambiguity also reemphasizes the fundamental distinction between trend detection and attribution (IPCC, 2007, chapter 1.3.3.), or similarly, between correlation and causality. In this study, no causal relationship can be formally inferred from the results, since only correlations (whether with time or with climate indices) are investigated. At the most, the lack of stability of temporal trends suggests that climate indices are better candidates to explain the temporal variability of low flows - but without demonstrating that it causes it. Merz et al. (2012) discuss this issue in further depth and propose avenues to move forward in the direction of attribution, which is in our opinion an important challenge to tackle. 


\subsection{Frequency analysis and the iid hypothesis}

The dependence of low flow regimes to large-scale climate variability may be problematic for standard frequency analyses approaches. As a matter of fact, standard methods assume independent and identically distributed (iid) observations. This hypothesis is inadequate if the distribution of low flow variables depends on some climate indices, as shown in this study.

The most problematic case occurs when this dependence is on a low-frequency mode of variability (e.g. the AMO). Indeed, the representativeness of hydrological series spanning over a few decades might be questionable due to the inertia of climate variability (see the discussion by e.g. Jain and Lall, 2001). There is, therefore, a distinct possibility to under- or over-estimate the actual hydrological risk, depending on the available record period.

This hurdle is well known for some areas of the world, where the impact of low-frequency climate variability on hydrological regimes is well documented. In the United States, regime shifts characterizing global climate oscillations and their potential impact in hydrology have been reported around 1970 (e.g. McCabe and Wolock, 2002; Mauget, 2003). In particular, Collins (2009) reported that, along the United States east coast, increasing flood magnitudes occurred in 1970, and are concurrent with a phase change in the low frequency variability of the NAO. The authors suggest that, when known, hydroclimatic shifts should be considered when the affected flow records are used for hydrological frequency analyses.

In Australia, the impact of the Interdecadal Pacific Oscillation (IPO) on hy- 
drology has been extensively reported (e.g. Franks, 2002; Franks and Kuczera, 2002), amongst other modes of climate variability (e.g. Keim and VerdonKidd, 2009). In order to overcome these difficulties, innovative frequency analysis approaches have been proposed (e.g. Micevski et al., 2006a,b; Thyer and Kuczera, 2000, 2003a,b; Verdon-Kidd and Kiem, 2010), and could be adapted to the context of France. In particular, such approaches explicitly integrate the role of climate variability, and attempt to make the best use of available long series at a regional scale.

\subsection{Seasonal forecasting}

The results obtained with seasonal climate indices yield interesting perspectives in terms of seasonal forecasting, which is a valuable tool for e.g. water resources management, hydropower management, and agriculture. For instance, the summer NAO has strong links with drought severity over northern France. This implies that, if one can predict the summer NAO, one can therefore infer drought severity for the same summer. This option is fairly limited by the overall prediction skill of the NAO, which is only satisfactory for periods of 1-2 weeks (Johansson, 2007). A better option would be to use the observed value of winter/spring WP2 and WP8, which could enable a direct seasonal forecast of the summer drought severity.

Developing such a seasonal forecasting system would require moving beyond the detection approach used in this study (which constitutes, however, a valuable preliminary step to identify compelling climate indices). It could build 
on the numerous examples of seasonal forecasting systems based on statistical relationships with large-scale climate variability existing in the literature (e.g. Sharma, 2000a; Sharma et al., 2000; Sharma, 2000b; Wilby et al., 2004; Westra et al., 2008; Lima and Lall, 2010; Gong et al., 2011). Moreover, investigating the role of additional climate indices might be valuable, since for instance the Mediterranean region displayed very few links with the climate indices used in this study. In particular, alternative WP classifications might be of interest (e.g. Cassou et al., 2004, 2005). The joint use of several complementary climate indices may also improve predictability.

Lastly, using statistical relationships between hydrological indices and largescale climate variability is not the sole approach to seasonal forecasting. In particular, an alternative is to use an atmospheric model to produce forecasts of climate forcings, and to use them as inputs of a hydrological model to produce hydrological forecasts (e.g. Ceron et al., 2010; Soubeyroux et al., 2010; Singla et al., 2012, for applications in France).

\subsection{Impact of climate change on hydrological droughts}

Another potential application of the hydro-climatic relationships highlighted in this study pertains to projecting the impact of climate change on low flows. The standard approach to this problem is to force a hydrological model with future forcings (e.g. precipitation, temperature) projected by a General Circulation Model (GCM), possibly after a downscaling or biascorrection procedure (see e.g. Vidal and Hendrickx, 2010; Hendrickx and 
Sauquet, 2012, for examples in France). A drawback of this approach is the difficulty to reliably reproduce some key variables for catchment hydrology (in particular, precipitation, Vidal and Wade, 2008). Moreover, the ability of hydrological models to extrapolate beyond the range of forcing conditions used for its calibration remains unclear (e.g., Merz et al., 2011).

An alternative approach would be to directly use the statistical relationships detected between hydrological and climate indices (similarly to seasonal forecasting, but without the requirement of asynchronicity). In other words, this approach would imply to directly downscale streamflow indices from climatic information. It could be beneficial provided that GCMs can reproduce atmospheric circulation and SST more reliably than forcings like precipitation. Moreover, it would imply that the statistical relationships held under climate change, which is the underlying hypothesis of any statistical downscaling method. Tisseuil et al. (2010) propose a review of such approaches and discuss why they have been so scarcely used compared to the standard approach. The interest of directly downscaling streamflow therefore deserves some evaluation, at least for temporally integrated indices such as the annual mean flow. For instance, the strong relationships detected between the mean annual flow and WP2/WP8 (Figure 5) might be used for future projections. For finer characteristics (e.g. annual minimum flow or volume deficit), the use of a hydrological model might be more difficult to circumvent. 


\section{Conclusions}

The present study aimed at performing a trend analysis for low flows in France and increase our understanding of the climate factors that affect the temporal variability of hydrological regimes. The main results can be summarized as follows:

- Drought Severity: temporal trends show a North-South geographical split, with an increase of drought severity in the southern half of France. A similar spatial pattern is observed for correlations with the AMO and the NAO. Consequently, it cannot be excluded that at least part of the temporal trends detected on drought regimes results from large scale climate variability and on its inertial behavior. Moreover, the frequency of the WP2 (Atlantic low pressure) and WP8 (high pressure) weather patterns seems to play a predominant role in the temporal variability of drought regimes over most of the country, except for the Mediterranean coastal region.

- Drought Timing: a large number of temporal trends were detected, especially for the drought start (occurring earlier in the year). However, unlike drought severity, the correlations with the AMO and the NAO do not bring about a similar spatial pattern. Furthermore, the role of the weather patterns WP2 and WP8 is less pronounced. As a result, the temporal trends detected on drought timing do not seem to be linked to large scale climate variability. 
In addition, the analysis carried out on a subset of longer series (60 years of data over the period 1948-2008) shows a quite good stability of the correlations with climate indices (when present), whereas temporal trends are much less robust, sometimes even contradictory, over different time periods. This result reveals the suitability of climate indices for explaining the temporal variability of hydrological regimes, and suggests that these indices are more relevant in the light of predictability than temporal trends.

Lastly, the use of seasonal climate indices allows for the identification of some specific hydro-climatic links. The main findings are the following:

- The use of seasonal NAO, WP2 and WP8 make some of the correlations stand out more prominently than their annual counterparts. This highlights the importance of considering these modes of variability at a finer scale (seasons).

- Notwithstanding the literature, especially at the Northern and Southern boundaries of Europe, the winter NAO shows very little correlation with drought severity. Thus France seems located in an area of weak influence of winter NAO.

- Several relationships based on seasonal climate indices are lagged, meaning that summer droughts are linked to the climate index of previous seasons. This result paves the way for interesting seasonal forecasting applications. 


\section{Acknowledgments}

This project was funded by the French National Agency for Water and Aquatic Environments (ONEMA). The hydrological time series were downloaded from the Banque Hydro database. We thank the data providers (DREAL, CNR, EDF, DDE, DDAF, SPC, SN and CA) for their invaluable assistance during data validation. Finally, we thank the three reviewers for their constructive and helpful comments.

Assani, A.A., Landry, R., Laurencelle, M., 2011. Comparison of interannual variability modes and trends of seasonal precipitation and streamflow in southern Quebec (Canada). River Research and Applications .

Birsan, M.V., Molnar, P., Burlando, P., Pfaundler, M., 2005. Streamflow trends in switzerland. Journal of Hydrology 314, 312-329.

Boé, J., Terray, L., 2008. A Weather-Type Approach to Analyzing Winter Precipitation in France: Twentieth-Century Trends and the Role of Anthropogenic Forcing. Journal of Climate 21, 3118-3133.

Bouwer, L.M., Vermaat, J.E., Aerts, J.C.J.H., 2008. Regional sensitivities of mean and peak river discharge to climate variability in Europe. Journal of geophysical research 113.

Bradford, R., Marsh, T., 2003. Defining a network of benchmark catchments for the uk. Proceedings of the Institution of Civil Engineers, Water and Maritime Engineering 156, 109-116. 
Burn, D.H., Elnur, M.A.H., 2002. Detection of hydrologic trends and variability. Journal of Hydrology 255, 107-122.

Cassou, C., 2004. Du changement climatique aux régimes de temps : l'Oscillation Nord-Atlantique. La Météorologie 45, 21-32.

Cassou, C., Terray, L., Hurrell, J.W., Deser, C., 2004. North atlantic winter climate regimes: Spatial asymmetry, stationarity with time, and oceanic forcing. Journal of Climate 17, 1055-1068.

Cassou, C., Terray, L., Phillips, A.S., 2005. Tropical atlantic influence on european heat waves. Journal of Climate 18, 2805-2811.

Ceron, J.P., Tanguy, G., Franchisteguy, L., Martin, E., Regimbeau, F., Vidal, J.P., 2010. Hydrological seasonal forecast over france: feasibility and prospects. Atmospheric Science Letters 11, 78-82.

Collins, M., 2009. Evidence for Changing Flood Risk in New England Since the Late 20th Century. Journal of the American Water Resources Association 45, 279-290.

Enfield, D.B., Cid-Serrano, L., 2009. Secular and multidecadal warmings in the North Atlantic and their relationships with major hurricane activity. International Journal of Climatology 30, 174-184.

Enfield, D.B., Mestas-Nuñez, A.M., Trimble, P.J., 2001. The Atlantic Multidecadal Oscillation and its relation to rainfall and river flows in the continental U.S. Geophysical Research Letters 28, 2077-2080. 
Fleig, A.K., Tallaksen, L.M., Hisdal, H., Hannah, D.M., 2011. Regional hydrological drought in north-western Europe: linking a new Regional Drought Area Index with weather types. Hydrological Processes 25, 11631179.

Fleig, A.K., Tallaksen, L.M., Hisdal, H., Stahl, K., Hannah, D.M., 2010. Inter-comparison of weather and circulation type classifications for hydrological drought development. Physics and Chemistry of the Earth, Parts A/B/C 35, 507-515.

Franks, S.W., 2002. Identification of a change in climate state using regional flood data. Hydrology and Earth System Sciences 6, 11-16.

Franks, S.W., Kuczera, G., 2002. Flood frequency analysis: Evidence and implications of secular climate variability, new south wales. Water Resources Research 38.

Garavaglia, F., Gailhard, J., Paquet, E., Lang, M., Garçon, R., Bernardara, P., 2010. Introducing a rainfall compound distribution model based on weather patterns sub-sampling. Hydrology and Earth System Sciences 14, $951-964$.

Garavaglia, F., Lang, M., Paquet, E., Gailhard, J., Garçon, R., Renard, B., 2011. Reliability and robustness of rainfall compound distribution model based on weather pattern sub-sampling. Hydrology and Earth System Sciences 15, 519-532. 
Giuntoli, I., Renard, B., Lang, M., 2012. Floods in france, in: Kundzewicz, Z.W. (Ed.), Changes in flood risk in Europe. IAHS Press, pp. 199-211.

Goldenberg, S.B., Landsea, C.W., Mestas-Nunez, A.M., Gray, W.M., 2001. The recent increase in Atlantic hurricane activity: causes and implications. Science 293, 474-479.

Gong, G., Wang, L., Lall, U., 2011. Climatic precursors of autumn streamflow in the northeast united states. International Journal of Climatology 31, $1773-1784$.

Hamed, K.H., Rao, A.R., 1998. A modified Mann-Kendall trend test for autocorrelated data. Journal of Hydrology 204, 182-196.

Hannaford, J., Buys, G., 2012. Trends in seasonal river flow regimes in the UK. Journal of Hydrology 475, 158-174.

Hannaford, J., Marsh, T., 2006. An assessment of trends in uk runoff and low flows using a network of undisturbed catchments. International Journal of Climatology 26, 1237-1253.

Hannaford, J., Marsh, T.J., 2008. High-flow and flood trends in a network of undisturbed catchments in the uk. International Journal of Climatology 28, 1325-1338.

Hannah, D.M., Demuth, S., van Lanen, H.A.J., Looser, U., Prudhomme, C., Rees, G., Stahl, K., Tallaksen, L.M., 2011. Large-scale river flow archives: 
importance, current status and future needs. Hydrological Processes 25, $1191-1200$.

Hendrickx, F., Sauquet, E., 2012. Impact of business-as-usual water management under climate change for the ariège river basin (france). Hydrological sciences Journal. In preparation. .

Hurrell, J., 1995. Decadal trends in the north atlantic oscillation: Regional temperatures and precipitation. Science 269, 676-679.

Hurrell, J., VanLoon, H., 1997. Decadal variations in climate associated with the north atlantic oscillation. Climatic Change 36, 301-326.

Huss, M., Hock, R., Bauder, A., Funk, M., 2010. 100-year mass changes in the Swiss Alps linked to the Atlantic Multidecadal Oscillation. Geophysical Research Letters 37, 1-5.

Huth, R., Beck, C., Philipp, A., Demuzere, M., Ustrnul, Z., Cahynova, M., Kysely, J., Tveito, O.E., 2008. Classifications of atmospheric circulation patterns recent advances and applications, in: Gimeno, L., GarciaHerrera, R., Trigo, R.M. (Eds.), Trends and Directions in Climate Research. Blackwell Publishing, Oxford. volume 1146 of Annals of the New York Academy of Sciences, pp. 105-152.

IPCC, 2007. Climate Change 2007: The Physical Science Basis. Contribution of Working Group I to the Fourth Assessment Report of the Intergovernmental Panel on Climate Change. Technical Report. 
Jain, S., Lall, U., 2001. Floods in a changing climate: Does the past represent the future? Water Resources Research 37, 3193-3205.

Johansson, A., 2007. Prediction Skill of the NAO and PNA from Daily to Seasonal Time Scales. Journal of Climate 20, 1957-1975.

Jones, P.D., Jonsson, T., Wheeler, D., 1997. Extension to the north atlantic oscillation using early instrumental pressure observations from gibraltar and south-west iceland. International Journal of Climatology 17, 1433 1450.

Jónsdóttir, J., Uvo, C., Snorrason, A., 2004. Multivariate analysis of Icelandic river flow and its relation to variability in atmospheric circulation, in: XIII Nordic Hydrological Conference, 8-12 August 2004, Tallinn, Estonia.

Kaczmarek, Z., 2003. The impact of climate variability on flood risk in Poland. Risk analysis 23, 559-566.

Keim, A., Verdon-Kidd, D.C., 2009. Climatic drivers of victorian streamflow: Is enso the dominant influence? Australian Journal of Water Resources 13.

Kendall, M., 1975. Rank correlation methods. Griffin, London.

Kendall, M.G., 1938. A new measure of rank correlation. Biometrika 30, 81-93. 
Kiely, G., 1999. Climate change in Ireland from precipitation and streamflow observations. Advances in water resources 23, 141-151.

Kingston, D.G., Hannah, D.M., Lawler, D.M., McGregor, G.R., 2006. Interactions between large-scale climate and river flow across the northern North Atlantic margin, in: IAHS-AISH publication. International Association of Hydrological Sciences, pp. 350-355.

Knight, J.R., 2005. A signature of persistent natural thermohaline circulation cycles in observed climate. Geophysical Research Letters 32, 2-5.

Knight, J.R., Folland, C.K., Scaife, A.A., 2006. Climate impacts of the Atlantic Multidecadal Oscillation. Geophysical Research Letters 33, 1-4.

Lavers, D., Prudhomme, C., Hannah, D.M., 2010. Large-scale climate, precipitation and British river flows: Identifying hydroclimatological connections and dynamics. Journal of Hydrology 395, 242-255.

Lima, C.H.R., Lall, U., 2010. Climate informed monthly streamflow forecasts for the brazilian hydropower network using a periodic ridge regression model. Journal of Hydrology 380, 438-449.

Limanówka, D., Nieckarz, Z., Pociask-Karteczka, J., 2002. The North Atlantic Oscillation impact on hydrological regime in Polish Carpathians, in: ERB and Northern European FRIEND Project 5 Conference, Demanovska dolina, Slovakia. 
Littmann, T., 2000. An empirical classification of weather types in the Mediterranean Basin and their interrelation with rainfall. Theoretical and applied climatology 66, 161-171.

Lorenzo, M.N., Taboada, J.J., Gimeno, L., 2008. Links between circulation weather types and teleconnection patterns and their influence on precipitation patterns in Galicia (NW Spain). International Journal of Climatology 28, 1493-1505.

Mann, H., 1945. Nonparametric tests against trend. Econometrica 13, 245259.

Martínez, C., Campins, J., Jansà, A., Genovés, A., 2008. Heavy rain events in the western mediterranean: an atmospheric pattern classification. Advances in Science and Research 2, 61-64.

Massei, N., Laignel, B., Deloffre, J., Mesquita, J., Motelay, A., Lafite, R., Durand, A., 2010. Long-term hydrological changes of the Seine River flow (France) and their relation to the North Atlantic Oscillation over the period 1950-2008. International Journal of Climatology 30, 2146-2154.

Mauget, S.A., 2003. Multidecadal Regime Shifts in US Streamflow, Precipitation, and Temperature at the End of the Twentieth Century. Journal of Climate 16, 3905-3916.

McCabe, G.J., Betancourt, J.L., Gray, S.T., Palecki, M.A., Hidalgo, H.G., 
2008. Associations of multi-decadal sea-surface temperature variability with us drought. Quaternary International 188, 31-40.

McCabe, G.J., Wolock, D.M., 2002. A step increase in streamflow in the conterminous United States. Geophysical Research Letters 29, 2185.

Merz, B., Vorogushyn, S., Uhlemann, S., Delgado, J., Hundecha, Y., 2012. Hess opinions "more efforts and scientific rigour are needed to attribute trends in flood time series". Hydrol. Earth Syst. Sci. Discuss. 9, 1345-1365. HESSD.

Merz, R., Parajka, J., Blöschl, G., 2011. Time stability of catchment model parameters: Implications for climate impact analyses. Water Resources Research 47, W02531.

Micevski, T., Franks, S.W., Kuczera, G., 2006a. Multidecadal variability in coastal eastern australian flood data. Journal of Hydrology 327, 219-225.

Micevski, T., Kuczera, G., Franks, S., 2006b. A bayesian hierarchical regional flood model, in: Australia, E. (Ed.), 30th Hydrology and Water Resources Symposium, Engineers Australia, Launceston, Tas, Australia.

Petrow, T., Zimmer, J., Merz, B., 2009. Changes in the flood hazard in Germany through changing frequency and persistence of circulation patterns. Natural Hazards and Earth System Science 9, 1409-1423.

Pettitt, A.N., 1979. A non-parametric approach to the change-point problem. Applied Statistics 28, 126-135. 
Philipp, A., Bartholy, J., Beck, C., Erpicum, M., Esteban, P., Fettweis, X., Huth, R., James, P., Jourdain, S., Kreienkamp, F., Krennert, T., Lykoudis, S., Michalides, S.C., Pianko-Kluczynska, K., Post, P., Alvarez, D.R., Schiemann, R., Spekat, A., Tymvios, F.S., 2010. Cost733cat-a database of weather and circulation type classifications. Physics and Chemistry of the Earth 35, 360-373.

Pociask-Karteczka, J., 2006. River Hydrology and the North Atlantic Oscillation: A General Review. AMBIO: A Journal of the Human Environment $35,312-314$.

Pociask-Karteczka, J., Nieckarz, Z., Limanówka, D., 2003. Prediction of hydrological extremes by air circulation indices. Water Resources SystemsWater Availability and Global Change, IAHS Publ. 280, 134-141.

Pongrácz, R., Bogardi, I., Duckstein, L., 2003. Climatic forcing of droughts: a Central European example. Hydrological Sciences Journal 48, 39-50.

Renard, B., Lang, M., Bois, P., Dupeyrat, A., Mestre, O., Niel, H., Sauquet, E., Prudhomme, C., Parey, S., Paquet, E., Neppel, L., Gailhard, J., 2008. Regional methods for trend detection: Assessing field significance and regional consistency. Water Resources Research 44.

Rimbu, N., Boroneant, C., Buta, C., Dima, M., 2002. Decadal variability of the Danube river flow in the lower basin and its relation with the North Atlantic Oscillation. International Journal of Climatology 22, 1169-1179. 
Rimbu, N., Dima, M., Lohmann, G., Stefan, S., 2004. Impacts of the North Atlantic Oscillation and the El Niño-Southern Oscillation on Danube river flow variability. Geophysical Research Letters 31, 2-5.

Rowell, D.P., 1996. Variability of summer rainfall over tropical north Africa (1906-92): Observations and modelling - Further analysis of simulated interdecadal and interannual variability of summer rainfall over tropical north Africa - Reply to comments. Quarterly Journal of the Royal Meteorological Society 122, 1007-1013.

Rowell, D.P., Folland, C.K., Maskell, K., Ward, N.M., 1995. Variability of summer rainfall over tropical north Africa (1906-92): Observations and modelling. Quarterly Journal of the Royal Meteorological Society 121, 669-704.

Samaniego, L., Bárdossy, A., 2007. Relating macroclimatic circulation patterns with characteristics of floods and droughts at the mesoscale. Journal of Hydrology 335, 109-123.

Sharma, A., 2000a. Seasonal to interannual rainfall probabilistic forecasts for improved water supply management: Part 1 - a strategy for system predictor identification. Journal of Hydrology 239, 232-239.

Sharma, A., 2000b. Seasonal to interannual rainfall probabilistic forecasts for improved water supply management: Part 3 - a nonparametric probabilistic forecast model. Journal of Hydrology 239, 249-258. 
Sharma, A., Luk, K.C., Cordery, I., Lall, U., 2000. Seasonal to interannual rainfall probabilistic forecasts for improved water supply management: Part 2 - predictor identification of quarterly rainfall using oceanatmosphere information. Journal of Hydrology 239, 240-248.

Shorthouse, C., Arnell, N., 1997. Spatial and temporal variability in European river flows and the North Atlantic Oscillation. FRIEND 97 - Regional Hydrology: Concepts and Models for Sustainable Water Resource Management, IAHS Publ. 246.

Singla, S., Céron, J.P., Martin, E., Regimbeau, F., Déqué, M., Habets, F., Vidal, J.P., 2012. Predictability of soil moisture and river flows over france for the spring season. Hydrology and Earth System Sciences 16, 201-216.

Soubeyroux, J.M., Vidal, J.P., Baillon, M., Blanchard, M., Ceron, J.P., Franchisteguy, L., Regimbeau, F., Martin, E., Vincendon, J.C., 2010. Characterizing and forecasting droughts and low-flows in france with the safranisba-modcou hydrometeorological suite. Houille Blanche-Revue Internationale De L Eau , 30-39.

Stahl, K., Demuth, S., 1999. Linking streamflow drought to the occurrence of atmospheric circulation patterns. Hydrological Sciences Journal 44, 467482.

Stahl, K., Demuth, S., Hisdal, H., Santos, M., Verissimo, R., Rodrigues, R., 2001. The North Atlantic Oscillation (NAO) and the drought, In: 
Assessment of the Regional Impact of Droughts in Europe. Final Report, ARIDE .

Stahl, K., Hisdal, H., Hannaford, J., Tallaksen, L.M., van Lanen, H.a.J., Sauquet, E., Demuth, S., Fendekova, M., Jódar, J., 2010. Streamflow trends in Europe: evidence from a dataset of near-natural catchments. Hydrology and Earth System Sciences 14, 2367-2382.

Stefan, S., Ghioca, M., Rimbu, N., Boroneant, C., 2004. Study of meteorological and hydrological drought in southern Romania from observational data. International Journal of Climatology 24, 871-881.

Stewart, I.T., Cayan, D.R., Dettinger, M.D., 2005. Changes toward Earlier Streamflow Timing across Western North America. Journal of Climate 18, $1136-1155$.

Sutton, R.T., Hodson, D.L.R., 2005. Atlantic Ocean forcing of North American and European summer climate. Science (New York, N.Y.) 309, 115-8.

Tallaksen, L.M., Van Lanen, H.A.J., 2004. Hydrological Drought: processes and estimation methods for streamflow and groundwater. volume 48. Elsevier.

Thyer, M., Kuczera, G., 2000. Modeling long-term persistence in hydroclimatic time series using a hidden state markov model. Water Resources Research 36, 3301-3310. 
Thyer, M., Kuczera, G., 2003a. A hidden markov model for modelling longterm persistence in multi-site rainfall time series 1 . model calibration using a bayesian approach. Journal of Hydrology 275, 12-26.

Thyer, M., Kuczera, G., 2003b. A hidden markov model for modelling longterm persistence in multi-site rainfall time series. 2. real data analysis. Journal of Hydrology 275, 27-48.

Tisseuil, C., Vrac, M., Lek, S., Wade, A.J., 2010. Statistical downscaling of river flows. Journal of Hydrology 385, 279-291.

Tourre, Y., Rousseau, D., Jarlan, L., Le Roy Ladurie, E., Daux, V., 2011. Western European climate and Pinot noir grape-harvest dates in Burgundy, France, since the 17th century. Climate Research 46, 243-253.

Trenberth, K.E., Shea, D.J., 2006. Atlantic hurricanes and natural variability in 2005. Geophysical Research Letters 33, 1-4.

Trigo, R.M., Pozo-Vázquez, D., Osborn, T.J., Castro-Díez, Y., Gámiz-Fortis, S., Esteban-Parra, M.J., 2004. North Atlantic oscillation influence on precipitation, river flow and water resources in the Iberian Peninsula. International Journal of Climatology 24, 925-944.

Verdon-Kidd, D.C., Kiem, A.S., 2010. Quantifying drought risk in a nonstationary climate. Journal of Hydrometeorology 11, 1019-1031.

Vicente-Serrano, S., Cuadrat, J., 2007. North Atlantic oscillation control of 
droughts in north-east Spain: evaluation since 1600 A.D. Climatic Change 85, 357-379.

Vidal, J., Hendrickx, F., 2010. Impact of climate change on hydropower: Ariège, france, in: Fung, F., Lopez, A., New, M. (Eds.), Modelling the Impact of Climate Change on Water Resources. Wiley-Blackwell, pp. 148161.

Vidal, J.P., Wade, S.D., 2008. Multimodel projections of catchment-scale precipitation regime. Journal of Hydrology 353, 143-158.

Wedgbrow, C.S., Wilby, R.L., Fox, H.R., O'Hare, G., 2002. Prospects for seasonal forecasting of summer drought and low river flow anomalies in England and Wales. International Journal of Climatology 22, 219-236.

Westra, S., Sharma, A., Brown, C., Lall, U., 2008. Multivariate streamflow forecasting using independent component analysis. Water Resources Research 44 .

Whitfield, P.H., Burn, D.H., Hannaford, J., Higgins, H., Hodgkins, G.a., Marsh, T., Looser, U., 2012. Reference hydrologic networks I. The status and potential future directions of national reference hydrologic networks for detecting trends. Hydrological Sciences Journal , 1-18.

Wilby, R., O'Hare, G., Barnsley, N., 1997. The North Atlantic Oscillation and British Isles climate variability, 1865-1996. Weather 52, 266-276. 
Wilby, R.L., Wedgbrow, C.S., Fox, H.R., 2004. Seasonal predictability of the summer hydrometeorology of the river thames, uk. Journal of Hydrology 295, 1-16.

Wilson, D., Hisdal, H., Lawrence, D., 2010. Has streamflow changed in the Nordic countries? - Recent trends and comparisons to hydrological projections. Journal of Hydrology 394, 334-346.

Wrzesinski, D., Paluszkiewicz, R., 2011. Spatial differences in the impact of the North Atlantic Oscillation on the flow of rivers in Europe. Hydrology Research 42, 30 . 
Table 1: Percentage of gauges with positive and negative correlations with error level $10 \%$.

\begin{tabular}{lrrrrrrrrrr}
\hline & \multicolumn{2}{c}{ Time } & \multicolumn{2}{c}{ AMO } & \multicolumn{2}{c}{ NAO } & \multicolumn{2}{c}{ WP2 } & \multicolumn{2}{c}{ WP8 } \\
\hline Correlation & Pos. & Neg. & Pos. & Neg. & Pos. & Neg. & Pos. & Neg. & Pos. & Neg. \\
\hline Drought severity & & & & & & & & & & \\
\hline AMean & 0.0 & 25.9 & 3.2 & 13.6 & 0.5 & 25 & 80 & 0.0 & 0.0 & 90.5 \\
AMin & 3.6 & 16.8 & 7.3 & 12.7 & 0.5 & 8.6 & 24.5 & 0.5 & 0.0 & 38.6 \\
Vol. Def. & 18.2 & 3.2 & 12.7 & 6.4 & 8.6 & 0.0 & 0.0 & 33.6 & 53.6 & 0.5 \\
\hline Drought timing & & & & & & & & & & \\
\hline Start & 0.0 & 30.5 & 3.2 & 11.8 & 0.0 & 5.5 & 13.6 & 0.0 & 0.0 & 31.4 \\
Center & 0.9 & 25.9 & 1.8 & 2.7 & 0.9 & 3.6 & 3.2 & 0.9 & 1.8 & 5.0 \\
End & 1.8 & 15.9 & 3.6 & 6.8 & 2.7 & 1.8 & 0.5 & 14.1 & 20.5 & 0.0 \\
\hline
\end{tabular}




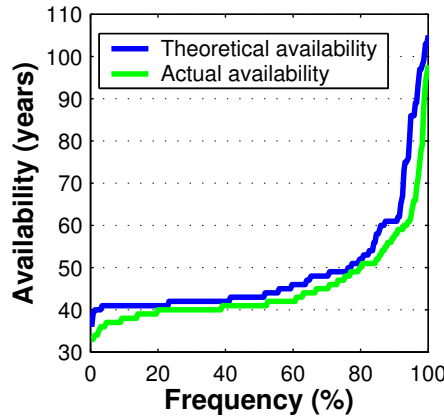

(a)

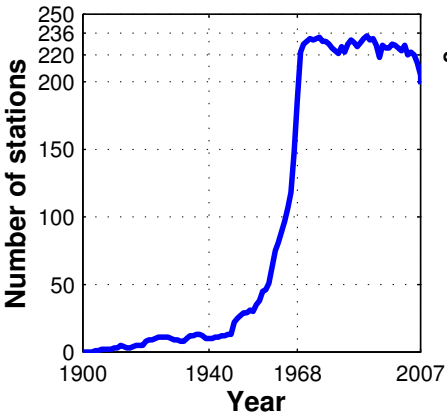

(b)

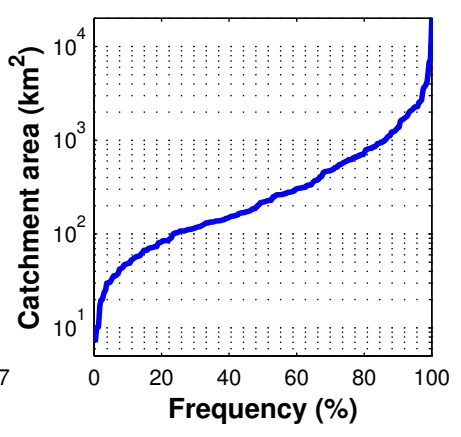

(c)

Figure 1: Properties of the dataset used in this study. (a) Distribution of the time series length. The "theoretical availability" refers to the life duration of the gauging station, while the "actual availability" holds once years with more than $10 \%$ of missing values are left out. (b) Number of stations available per year. (c) Distribution of catchment areas. 

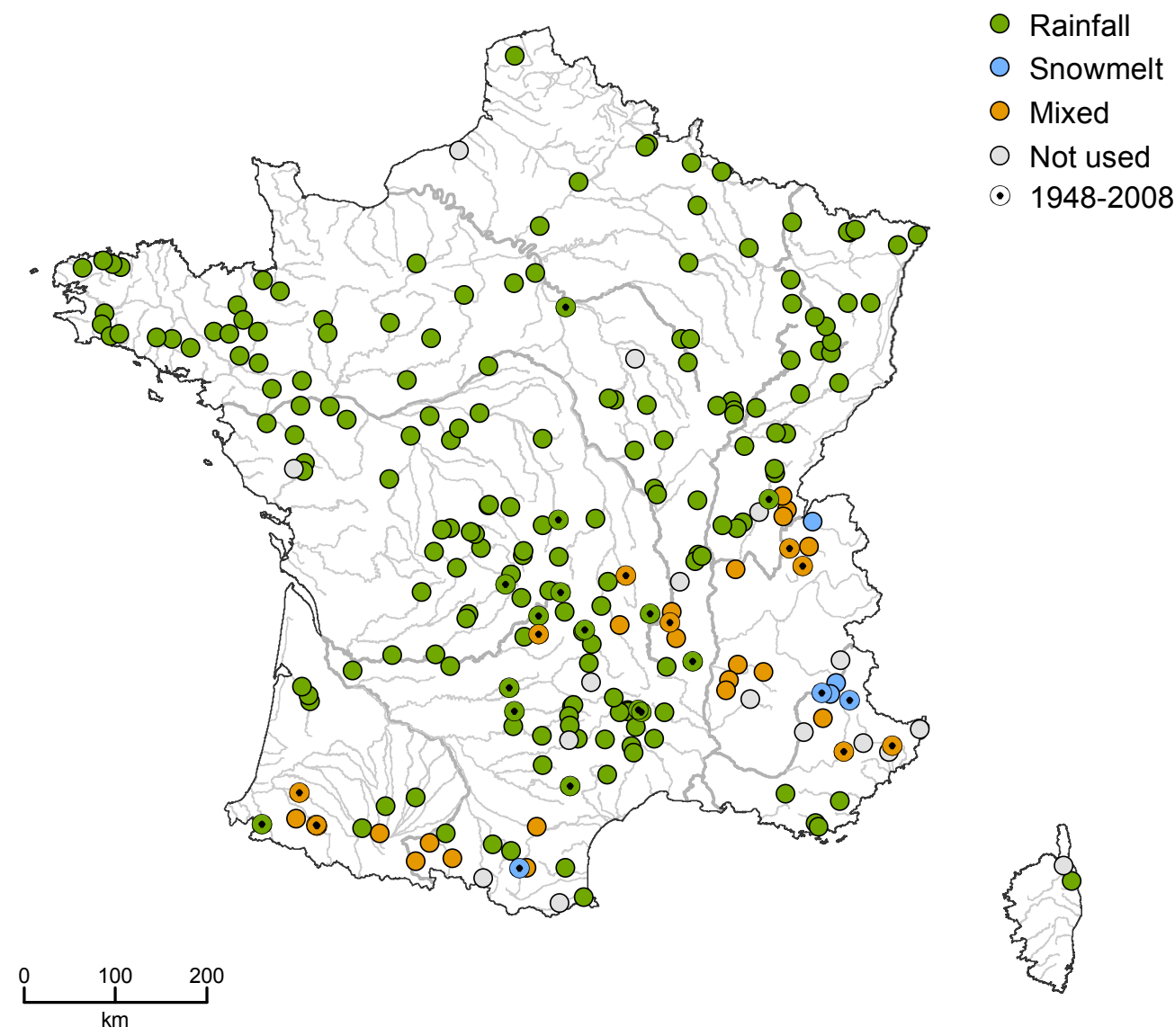

O Snowmelt

O Not used

$\odot 1948-2008$

Figure 2: Location of gauging stations and hydrological regime of associated catchments. Stations in gray (16) are part of the benchmark network, but were not used in this study due to insufficient coverage over the period 1968-2008. Stations "1948-2008" (28) provide additional coverage. 
Author-produced version of the article published in Journal of Hydrology (2013), vol. 482, p.105-118 The original publication is available at http://www.sciencedirect.com, doi: 10.1016/j.jhydrol.2012.12.038

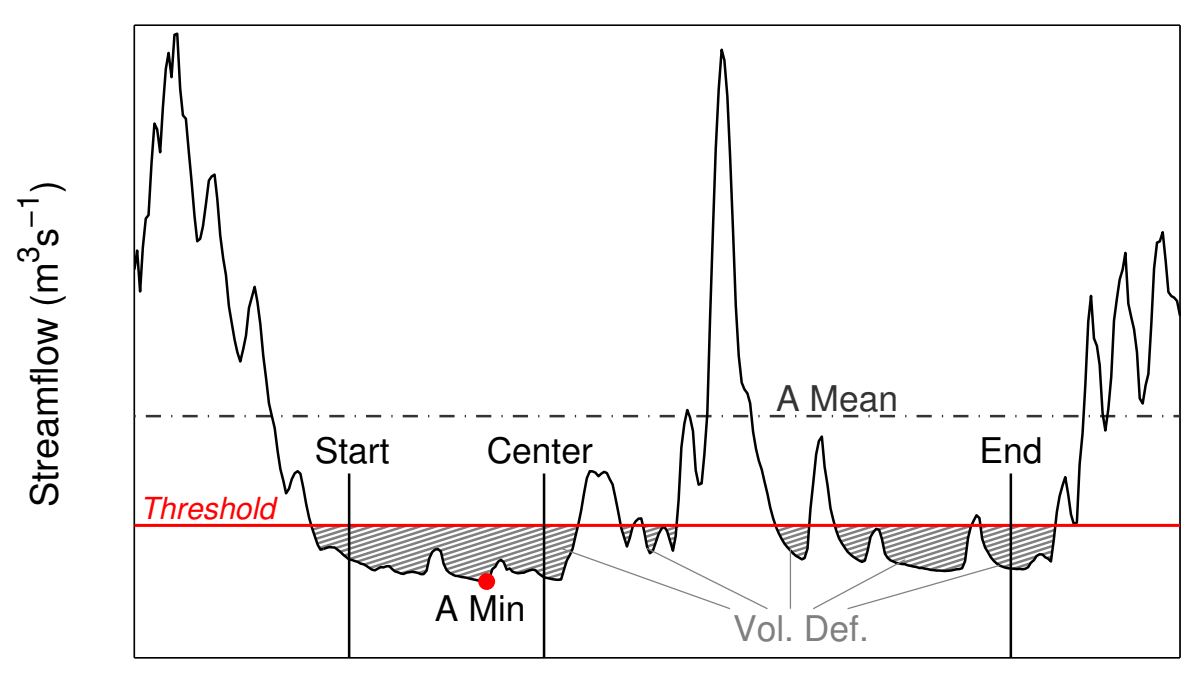

Time (hydrological year)

Figure 3: Schematic of drought indices. 


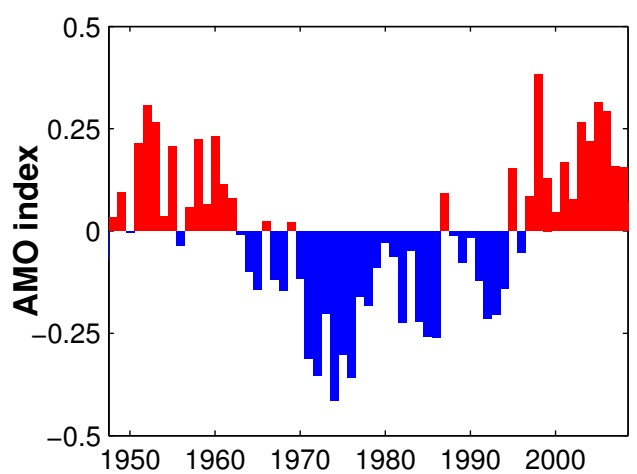

(a)

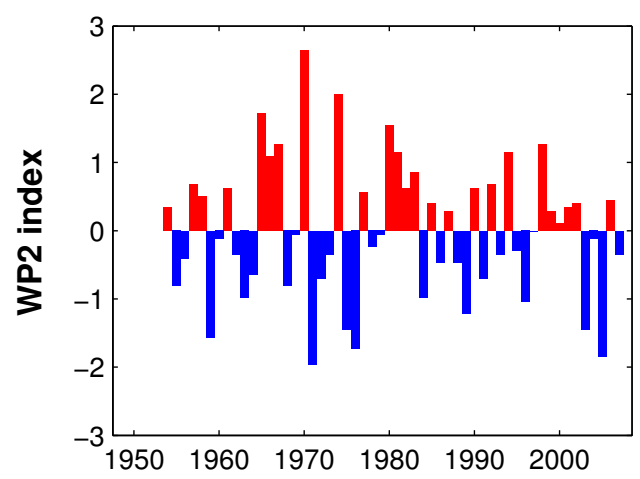

(c)

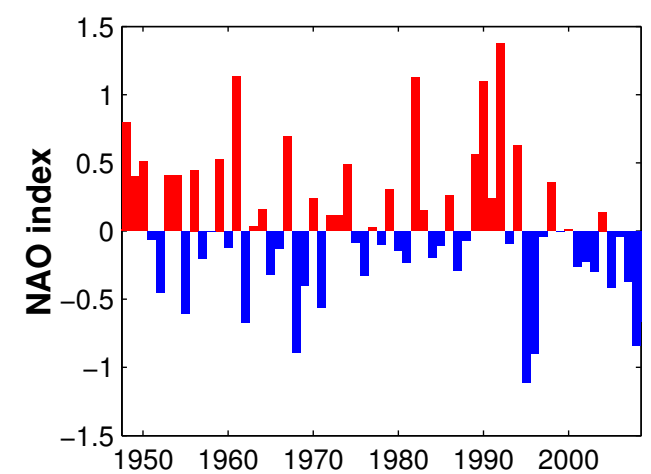

(b)

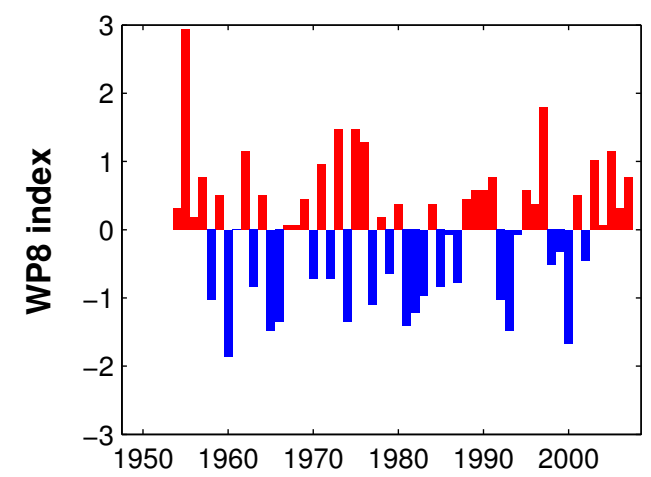

(d)

Figure 4: Time series of climate indices at the annual scale. (a) AMO; (b) NAO; (c) WP2; (d) WP8. Hydrological years corresponding to the rainfall regime (February - January) are used here. 

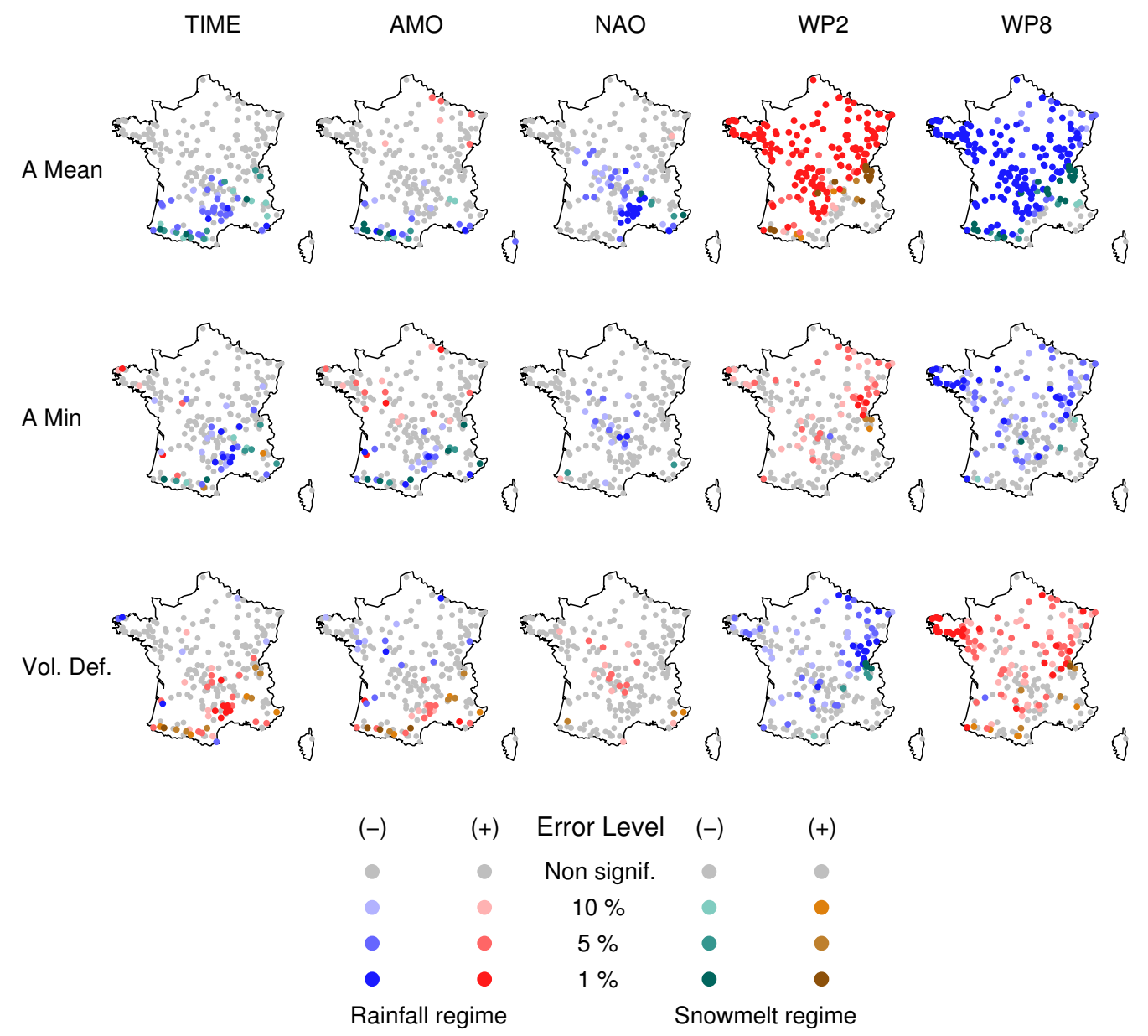

Figure 5: Results of the correlation analysis carried out on an annual basis: severity drought indices (rows) vs. climate indices (columns). 

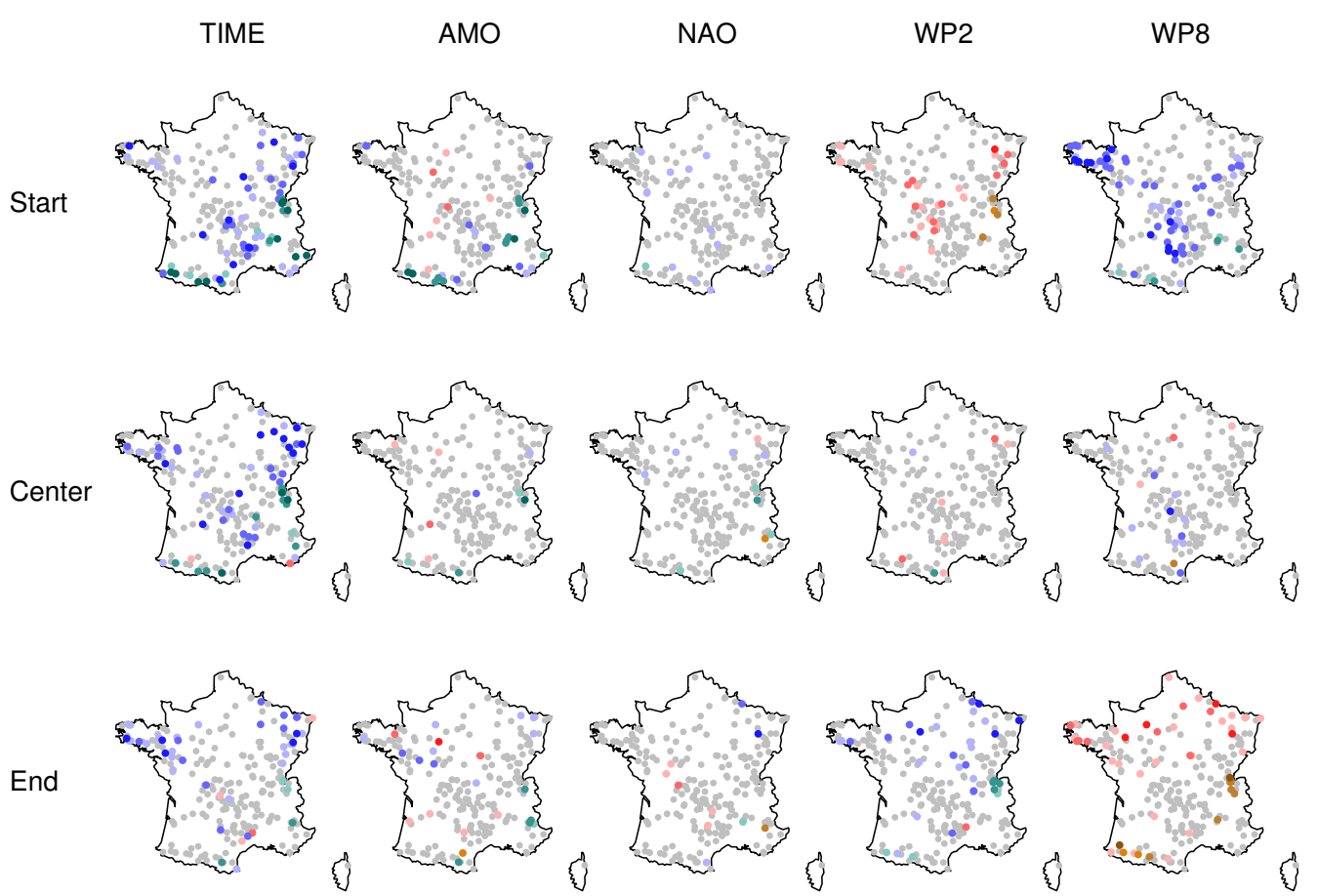

Figure 6: Results of the correlation analysis carried out on an annual basis: timing drought indices (rows) vs. climate indices (columns). Legend as in Figure 5. 


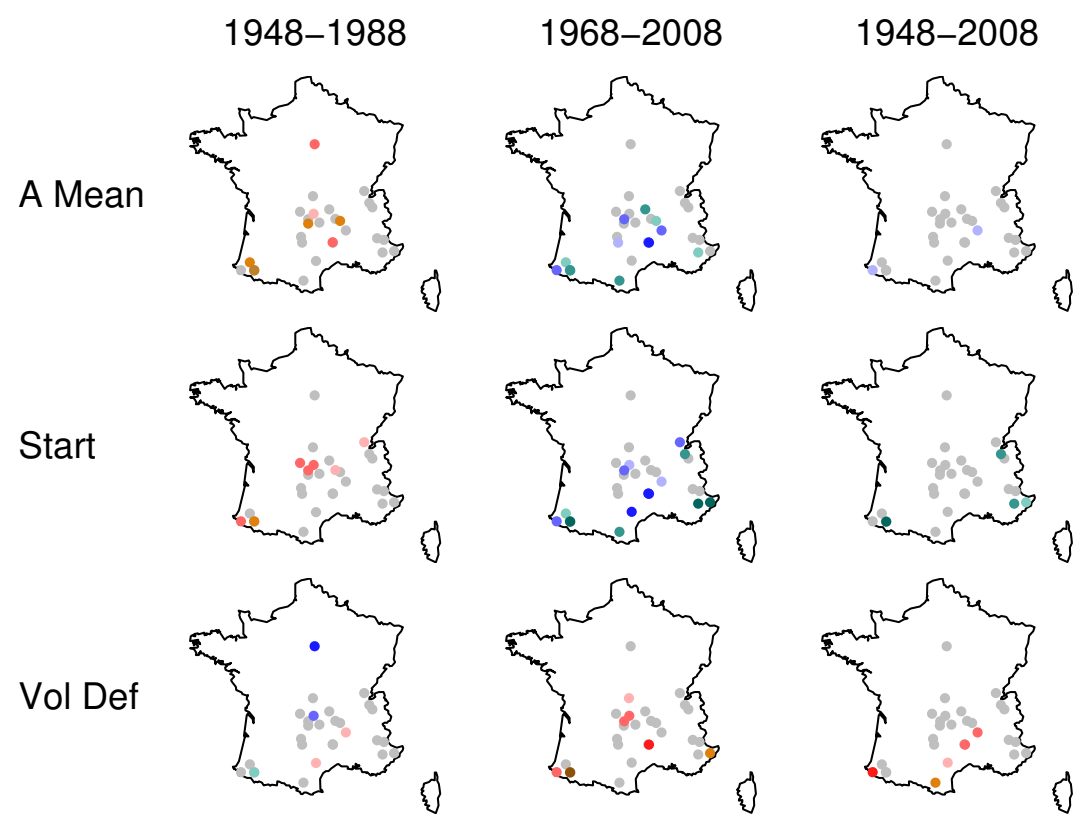

Figure 7: Results of the correlation analysis with respect to time, for three drought indices and three periods 1948-1988, 1968-2008, and 1948-2008. Legend as in Figure 5. 


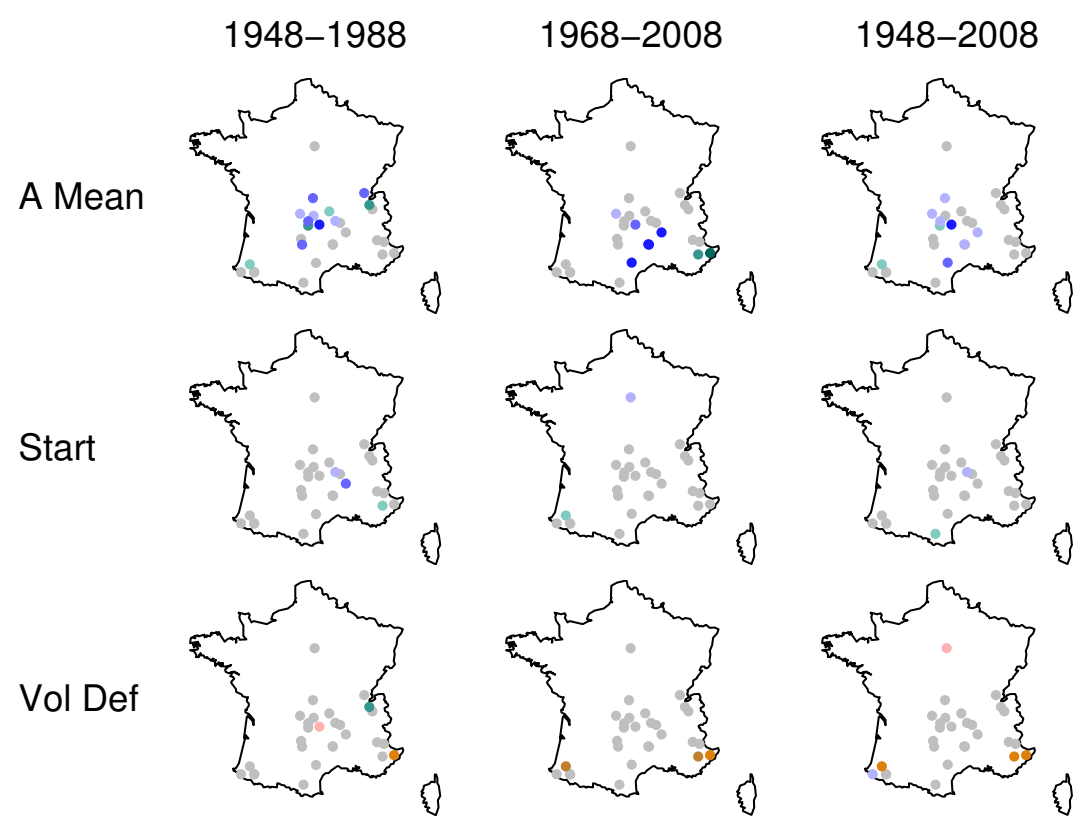

Figure 8: Results of the correlation analysis with respect to NAO, for three drought indices and three periods 1948-1988, 1968-2008, and 1948-2008. Legend as in Figure 5. 


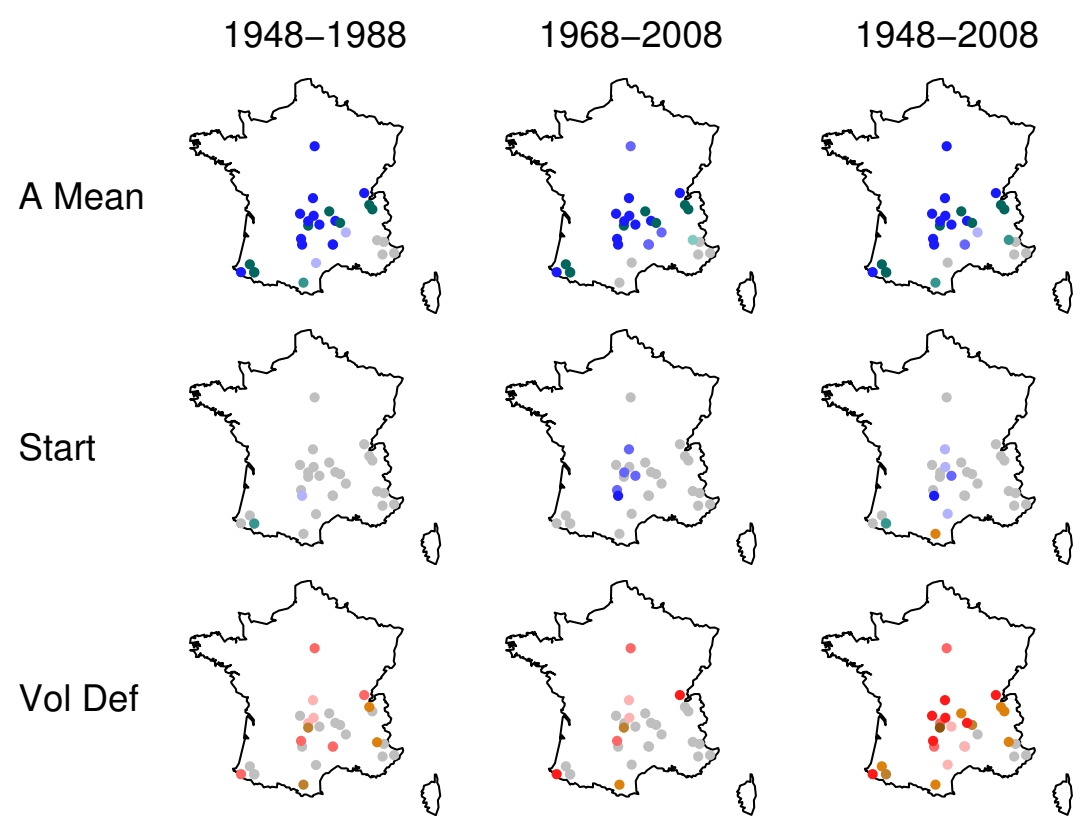

Figure 9: Results of the correlation analysis with respect to WP8, for three drought indices and three periods 1948-1988, 1968-2008, and 1948-2008. Legend as in Figure 5. 


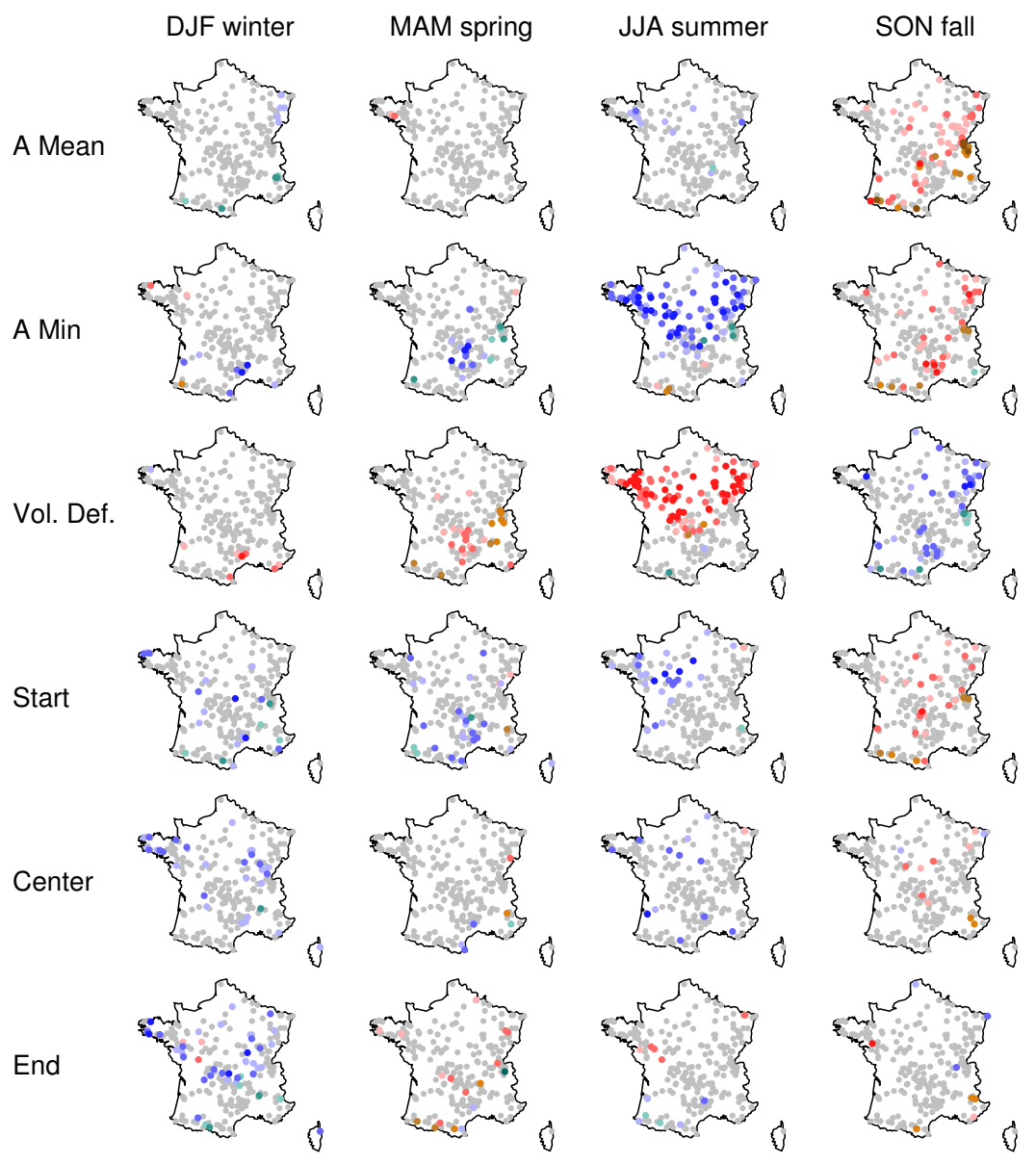

Figure 10: Results of the correlation analysis with respect to seasonal NAO. Legend as in Figure 5 . 


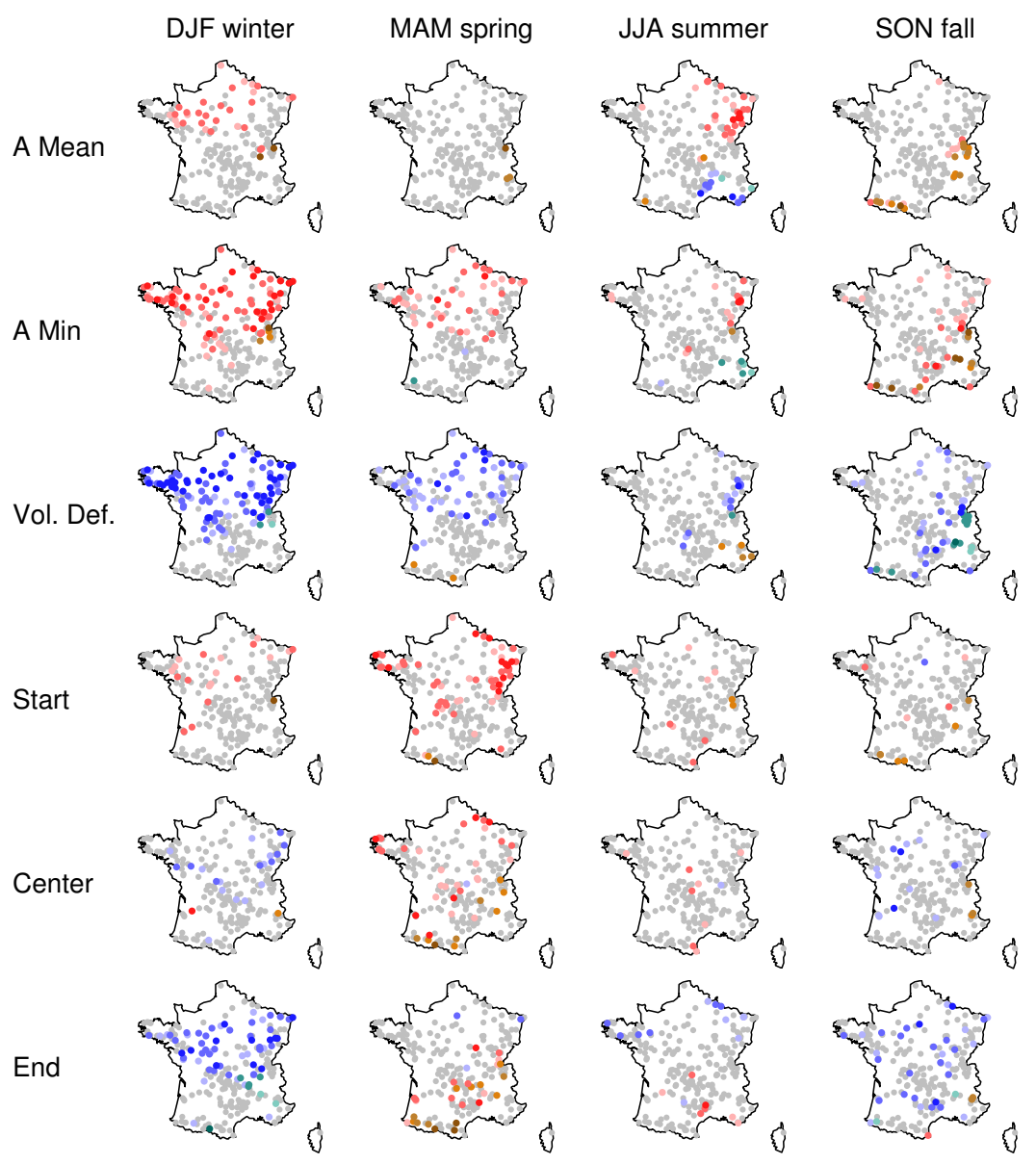

Figure 11: Results of the correlation analysis with respect to seasonal WP2. Legend as in Figure 5 . 


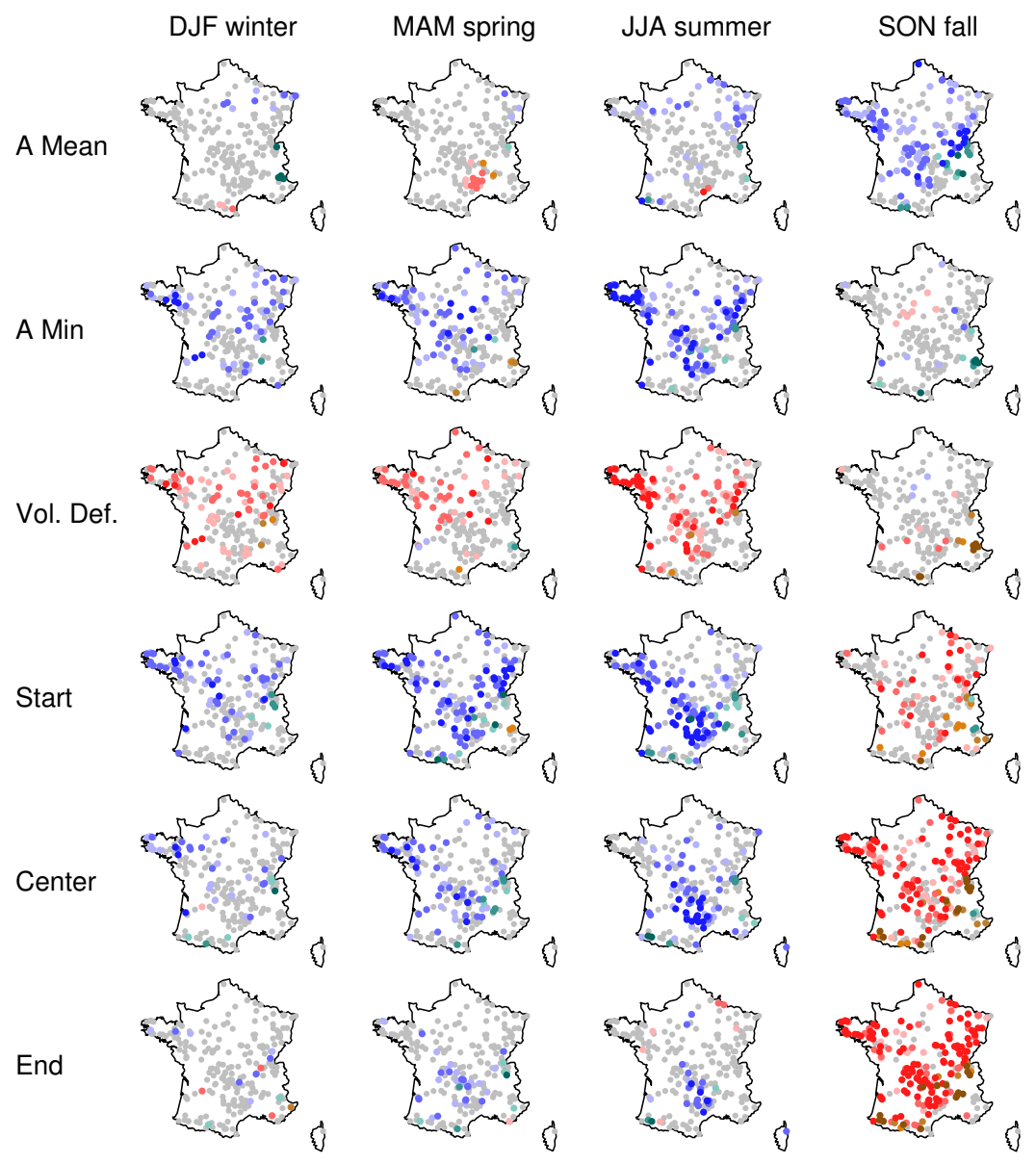

Figure 12: Results of the correlation analysis with respect to seasonal WP8. Legend as in Figure 5 . 